\title{
Germinação sob altas temperaturas para avaliação do potencial fisiológico de sementes de milho
}

\author{
Germination at high temperatures in evaluation of maize vigor
}

\author{
Cesar Augusto Gasparetto Sbrussi ${ }^{\mathrm{I}}$ Claudemir Zucareli $^{\mathrm{II}}$
}

\section{RESUMO}

O objetivo do trabalho foi avaliar e padronizar $o$ teste de germinação sob altas temperaturas para avaliação do vigor de sementes de milho. Foram utilizados seis lotes de sementes de milho híbrido com diferentes niveis de vigor $e$ potenciais germinativos semelhantes em três temperaturas (31, 34 e $37^{\circ} \mathrm{C}$ ), em esquema fatorial $3 x 6$, com quatro repetições. Além da caracterização da qualidade fisiológica pelos métodos padrão, foram determinados, sob altas temperaturas, a germinação, primeira contagem, comprimento e massa seca da raiz e parte aérea das plântulas. Os dados foram submetidos à análise de variância, comparação de médias pelo teste de Tukey e estudo de correlação linear simples a 5\%, respectivamente. As temperaturas de 31,34 e $37^{\circ} \mathrm{C}$ mostraram-se eficientes para a avaliação do vigor de lotes de sementes de milho. A temperatura de $34^{\circ} \mathrm{C}$ mostrouse mais adequada para avaliação do potencial fisiológico de sementes de milho, com maiores valores de correlação com os testes laboratoriais e com a emergência e indice de velocidade de emergência de plântulas no campo.

Palavras-chave: Zea mays, vigor, estresse térmico, análise de sementes.

\section{ABSTRACT}

The objective of the experiment was to evaluate and standardize the germination test under high temperatures to evaluate the vigor of corn seeds. For the experiment it was used six batches of hybrid corn seeds with different levels of vigor and similar germination potential. After the initial characterization of the lots, it was evaluated the influence of temperature of 31 , 34 and $37^{\circ} \mathrm{C}$ on germination, first count, length and dry mass of roots and shoots with lots of different levels of force. Data were subjected to analysis of variance and means were compared by Tukey test at 5\%, in $3 x 6$ factorial, which corresponded to three combinations of temperatures and six seed lots. The first count, the percentage of germination, length and dry mass, obtained at different temperatures along with the initial characterization data were submitted to the study of simple linear correlation at $5 \%$ significance. Temperatures of 31,34 and $37^{\circ} \mathrm{C}$ proved to be efficient for the evaluation of maize seed vigor, with emphasis on the temperature of $34^{\circ} \mathrm{C}$ which showed higher correlation with laboratory tests of the initial characterization of the lots and also with data emergency and the speed of the emergency field.

Key words: Zea mays, physiological potential, thermal stress, seed analysis.

\section{INTRODUÇ̃̃̃O}

Os testes de vigor são capazes de detectar, com maior precisão que o teste de germinação, os avanços da deterioração das sementes, permitindo diferenciar fisiologicamente lotes de poder germinativo semelhantes (MENDONÇA et al., 2008). Utilizados frequentemente pelas companhias produtoras de sementes de grandes culturas, os testes de vigor procuram destacar lotes com maior eficiência para o estabelecimento do estande sob ampla variação das condições de ambiente (MARCOS FILHO et al., 2009).

No Brasil, o teste de frio é amplamente utilizado para sementes de milho, principalmente nos Estados do Sul e Sudeste, onde lavouras de algodão, milho e soja podem ser semeadas no início do mês de setembro (CASEIRO \& MARCOS FILHO 2002), sendo comum a ocorrência de frentes frias chuvosas (KRZYZANOWSKI et al., 1991). Semelhante ao

'Programa de Pós-graduação em Fitotecnia, Universidade Estadual de Londrina (UEL), CP 10001, 86057-970, Londrina, PR, Brasil. E-mail: cesarsbrussi@yahoo.com.br. Autor para correspondência.

ID Departamento de Agronomia/Fitotecnia, UEL, Londrina, PR, Brasil. 
teste de frio, a germinação sob baixa temperatura também é amplamente utilizada e tem como princípio o fato de que baixas temperaturas, principalmente nos estágios iniciais de embebição, têm efeitos prejudiciais na germinação e no desenvolvimento das plântulas (KRZYZANOWSKI et al., 1999).

Entretanto, no Brasil, predominam climas quentes e úmidos (INMET, 2008), sendo estas as condições normais de semeadura. Nesse contexto, a temperatura do solo, principalmente para semeaduras tardias de milho de verão (novembro/dezembro) e para o milho safrinha (fevereiro/março), em geral, são elevadas, prejudicando a emergência das plântulas.

A exposição das sementes de milho em altas temperaturas durante o teste de germinação, por um período suficiente de tempo, proporciona danos irreversíveis no desenvolvimento das plântulas, acarretando em menores porcentagens de germinação e emergência (HALL 2001). Assim, considerando as condições tropicais de cultivo de milho no Brasil, bem como a expansão do milho safrinha, implantado no final do verão, a tolerância às altas temperaturas de germinação pode apresentar correlação com o desempenho no campo, podendo ser utilizado com eficiência como teste de avaliação do vigor de sementes.

Embora o procedimento básico para a condução de vários testes de vigor esteja estabelecido e produza resultados confiáveis, sempre há espaço para aprimoramento da metodologia ou inclusão de alternativas inovadoras (MARCOS FILHO et al., 2009), visto a necessidade de padronização de metodologias e de critérios para a interpretação de resultados (MENDONÇA et al., 2008). Nesse contexto, objetivou-se avaliar e padronizar a germinação sob temperaturas elevadas como um teste de vigor indicativo do desempenho das sementes de milho em campo.

\section{MATERIAL E MÉTODOS}

O experimento foi conduzido no Laboratório de Análise de Sementes do Departamento de Agronomia da Universidade Estadual de Londrina (UEL), Londrina-PR. Foram utilizados seis lotes de sementes de milho híbrido BALU 580 , com diferentes níveis de vigor e potenciais germinativos semelhantes, tratados com inseticidas (pirimifós-metílico 50\% 0,016 $\mathrm{L}_{\text {ton }}{ }^{-1}$ e Deltamethrin 2,5\% 0,04 $\mathrm{L} \mathrm{ton}^{-1}$ ) e fungicida (Metalaxyl-M 1,0\%+ Fludioxonil 2,5\% 1,00L ton ${ }^{-1}$ ) e corante vermelho na concentração $0,20 \mathrm{~L} \mathrm{ton}^{-1}$.
Inicialmente, realizou-se a caracterização da qualidade fisiológica inicial dos lotes de sementes, visando à separação destes em classes de vigor, mediante as seguintes avaliações fisiológicas: massa de mil sementes, germinação, primeira contagem e comprimento de plântula (BRASIL, 2009), teste de frio, envelhecimento acelerado, condutividade elétrica e tetrazólio (DIAS \& BARROS, 1995), massa seca de plântulas e índice de velocidade de emergência das plântulas (NAKAGAWA, 1999) e emergência da plântula em campo (NAKAGAWA, 1994).

Após a caracterização inicial dos lotes, o teste foi conduzido com quatro repetições de 100 sementes, em papel toalha umedecido na proporção de 2,5 vezes a massa do substrato seco (BRASIL, 2009). Os rolos de papel foram acondicionados em sacos plásticos e mantidos em uma câmara de germinação à temperatura de 31,34 e $37^{\circ} \mathrm{C}$. As avaliações foram realizadas, aos quatro e sete dias após a instalação do teste, computando-se a porcentagem de plântulas normais na primeira contagem, germinação, plântulas anormais e sementes não germinadas.

Os dados foram submetidos à análise de variância e as médias comparadas pelo teste de Tukey a 5\% de probabilidade, em esquema fatorial $3 \times 6$, correspondente a combinações de três temperaturas e seis lotes de sementes. Os resultados do teste de primeira contagem, porcentagem de germinação, massa seca e comprimento de raízes e parte aérea, obtidos para cada tratamento, juntamente com os dados da caracterização inicial, foram submetidos ao estudo de correlação linear simples a 5\% de significância.

\section{RESULTADOS E DISCUSSÃO}

A análise conjunta dos dados da caracterização inicial permitiu classificar os lotes em três níveis de vigor (Tabelas 1 e 2). O lote L6 e os lotes L1 e L2 mostraram-se significativamente superiores (alto vigor) e inferiores (baixo vigor), respectivamente, sendo os lotes L3, L4 e L5 identificados como de vigor intermediário. Não se espera que apenas um teste tenha a capacidade de detectar o comportamento das sementes, pois o próprio conceito de vigor destaca um "conjunto de características" distintas. Assim, a escolha inadequada do método, em função dos objetivos pretendidos, e o uso de apenas um teste, podem gerar informações incompletas a respeito do lote de sementes (MARCOS FILHO, 2005).

Ciência Rural, v.45, n.10, out, 2015. 
Tabela 1 - Valores médios da primeira contagem (P.C), germinação (G), massa seca de raízes (M.S.R), massa seca da parte aérea (M.S.PA), comprimento de raízes (C.R), comprimento da parte aérea (C.PA) da caracterização inicial de qualidade fisiológica de seis lotes de milho BALU-580, Londrina, 2012.

\begin{tabular}{|c|c|c|c|c|c|c|}
\hline LOTES & PC (\%) & G. $(\%)$ & M.S.R (g) & M.S.PA (g) & C.R (cm) & C.PA $(\mathrm{cm})$ \\
\hline L1 & $57 \mathrm{~d}$ & 88 & $0,2085 \mathrm{e}$ & $0,2336 \mathrm{~d}$ & $4,5 \mathrm{c}$ & $2,0 \mathrm{c}$ \\
\hline $\mathrm{L} 2$ & $76 \mathrm{c}$ & 88 & $0,3258 \mathrm{~d}$ & $0,3257 \mathrm{~cd}$ & $6,1 \mathrm{~b}$ & $3,0 \mathrm{~b}$ \\
\hline L3 & $83 \mathrm{~b}$ & 94 & $0,4085 \mathrm{c}$ & $0,3792 \mathrm{c}$ & $6,4 \mathrm{~b}$ & $3,0 \mathrm{~b}$ \\
\hline L4 & $94 \mathrm{a}$ & 95 & $0,5306 \mathrm{~b}$ & $0,5268 \mathrm{~b}$ & $7,7 \mathrm{a}$ & $3,4 a b$ \\
\hline L5 & $88 \mathrm{ab}$ & 94 & $0,5231 \mathrm{~b}$ & $0,5635 \mathrm{~b}$ & $7,5 \mathrm{a}$ & $3,6 a b$ \\
\hline L6 & $94 \mathrm{a}$ & 98 & $0,6958 \mathrm{a}$ & $0,6707 \mathrm{a}$ & $8,2 \mathrm{a}$ & $3,7 \mathrm{a}$ \\
\hline $\mathrm{CV}$ & 3,58 & 1,32 & 7,65 & 10,15 & 6,88 & 9,37 \\
\hline
\end{tabular}

Médias seguidas de mesma letra nas colunas não diferem entre si pelo teste de Tukey $(\mathrm{P}<0,05)$.

Observaram-se diferenças significativas entre os lotes em todas as temperaturas e características avaliadas, com exceção da temperatura de $37^{\circ} \mathrm{C}$, para as variáveis comprimento e massa seca de raízes. A influência do vigor, segundo CARVALHO \& NAKAGAWA (2000), é marcante sobre todos os aspectos do processo germinativo, desde a própria possibilidade de germinação até a velocidade de germinação, tamanho e massa das plântulas.

Em relação às diferenças entre lotes, observa-se, no geral, a superioridade do lote L6 e a inferioridade dos lotes L1 e L2, corroborando os resultados de vigor obtidos na caracterização inicial dos lotes. A habilidade de uma semente germinar sob amplo limite de condições é definida como a manifestação do seu vigor, dependendo, entre outros fatores, das condições ambientais encontradas no local onde foi semeada (SIMONI et al., 2011), justificando a superioridade do lote L6 quanto ao desempenho sob temperaturas acima da ideal para germinação.

Observa-se também redução no potencial germinativo das sementes, à medida que a temperatura de germinação aumenta. A temperatura de $37^{\circ} \mathrm{C}$ mostrou-se drástica para todos os lotes de sementes, acarretando em decréscimos substanciais no potencial germinativo (Tabela 3). Apesar da drasticidade nas condições térmicas de germinação, o lote L6, com alto vigor, sobressaiu-se em relação aos demais, indicando maior tolerância ao estresse.

O uso da temperatura adequada é, segundo PESKE (2003), um dos fatores mais importantes para a germinação, sendo que sementes de alta qualidade terão maior amplitude de temperatura para germinar do que aquelas de baixa qualidade. Isso explica as maiores porcentagens de germinação do lote L6 e indica a germinação sob altas temperaturas como um teste promissor para avaliação do vigor de sementes.

As características avaliadas após a germinação sob a temperatura de $31^{\circ} \mathrm{C}$ correlacionouse com a maioria das características avaliadas na caracterização da qualidade fisiológica inicial dos lotes, com exceção ao comprimento de raízes com o envelhecimento acelerado; comprimento da parte aérea com o teste de frio, o envelhecimento acelerado, a massa seca da raiz, o comprimento da parte aérea e a emergência a campo (Tabela 4).

Correlações significativas também foram encontradas na temperatura de $34^{\circ} \mathrm{C}$, sendo nesta

Tabela 2 - Valores médios do teste de frio (T.F), envelhecimento acelerado (E.A), tetrazólio (TZ), condutividade elétrica (C.E), emergência a campo (E.C) e índice de velocidade de emergência (I.V.E) da caracterização inicial de qualidade fisiológica de seis lotes de milho BALU-580. Londrina, 2012.

\begin{tabular}{|c|c|c|c|c|c|c|}
\hline LOTES & TF (\%) & E.A (\%) & $\mathrm{TZ}(\%)$ & $\mathrm{CE}(\mu \mathrm{S} / \mathrm{cm} / \mathrm{g})$ & E.C (\%) & IVE \\
\hline L1 & $54 \mathrm{~d}$ & $19 \mathrm{e}$ & $45 \mathrm{c}$ & $19,59 \mathrm{c}$ & $79 \mathrm{~b}$ & $3,19 \mathrm{~d}$ \\
\hline L2 & $43 \mathrm{e}$ & $48 \mathrm{~d}$ & $70 \mathrm{~b}$ & $19,43 \mathrm{c}$ & $80 \mathrm{~b}$ & $3,51 \mathrm{~cd}$ \\
\hline L3 & $70 \mathrm{c}$ & $61 \mathrm{~cd}$ & $71 \mathrm{~b}$ & $15,17 \mathrm{~b}$ & $89 a$ & $3,94 \mathrm{bc}$ \\
\hline $\mathrm{L} 4$ & $76 \mathrm{bc}$ & $68 \mathrm{bc}$ & $80 \mathrm{ab}$ & $16,45 \mathrm{~b}$ & $92 \mathrm{a}$ & $4,42 \mathrm{a}$ \\
\hline L5 & $83 a b$ & $79 a b$ & $71 \mathrm{~b}$ & $16,83 \mathrm{bc}$ & $93 \mathrm{a}$ & $4,34 \mathrm{ab}$ \\
\hline L6 & $91 \mathrm{a}$ & $86 \mathrm{a}$ & $84 a$ & $12,38 \mathrm{a}$ & $96 \mathrm{a}$ & $4,62 \mathrm{a}$ \\
\hline $\mathrm{CV}$ & 6,28 & 12,8 & 6,72 & 7,41 & 4,15 & 5,13 \\
\hline
\end{tabular}


Tabela 3 - Primeira contagem da germinação, comprimento de raízes, massa seca da parte aérea, germinação, comprimento da parte aérea e massa seca de raízes de lotes de sementes de milho, híbrido Balu-580, submetidos ao teste de germinação em altas temperaturas. Londrina, 2012.

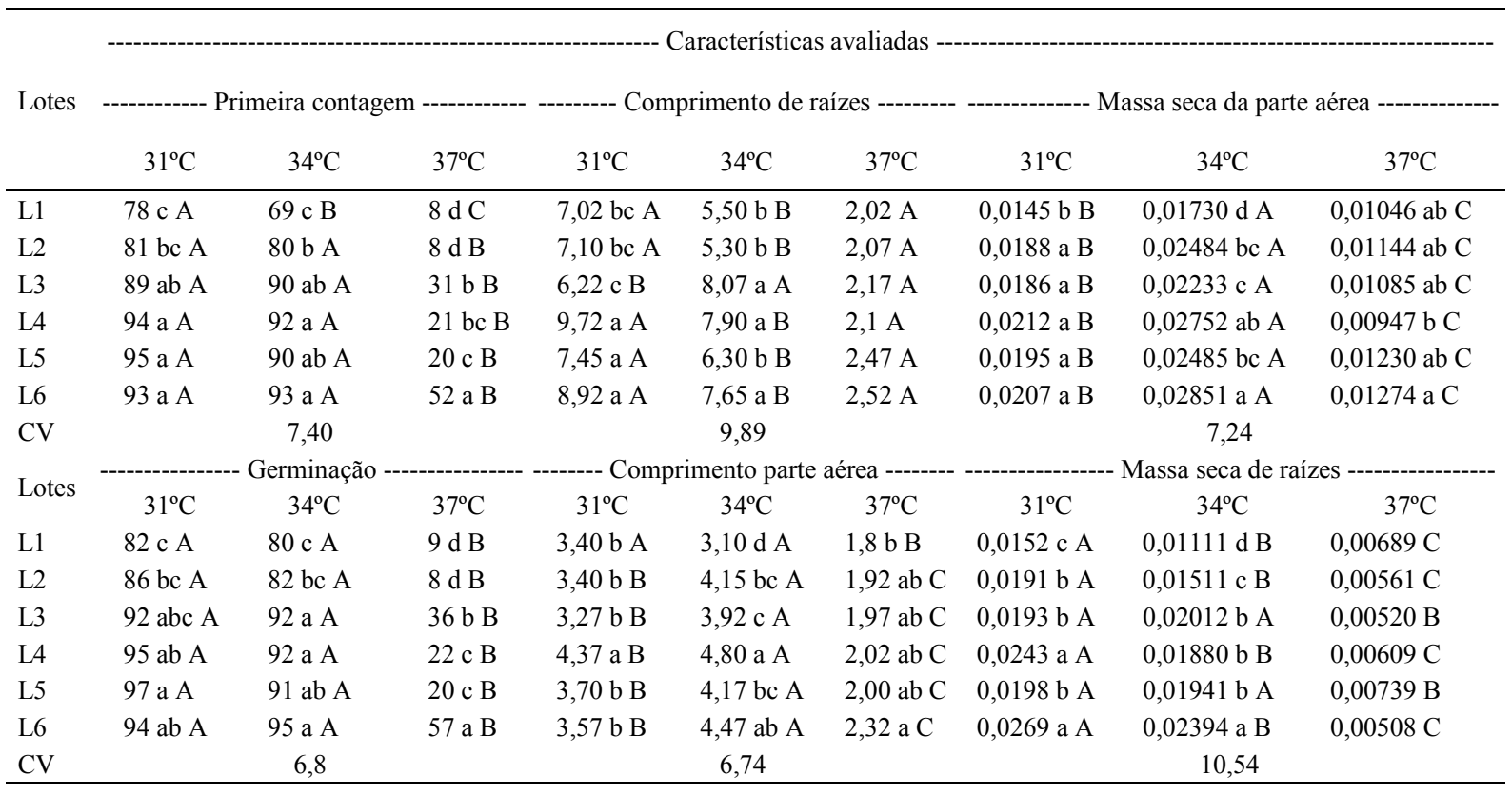

Médias seguidas de mesma letra, minúsculas nas colunas e maiúsculas na linha, dentro de cada característica, não diferem entre si pelo teste de Tukey $(\mathrm{P}<0,05)$.

observados os maiores valores de correlação em relação às temperaturas de 31 e $37^{\circ} \mathrm{C}$ (Tabela 5). Nesta temperatura, apenas não se correlacionou estatisticamente a combinação comprimento de raízes com a parte aérea determinada na caracterização inicial $\left(25^{\circ} \mathrm{C}\right)$.

$\mathrm{Na}$ escolha do método de avaliação do vigor das sementes, devem-se observar os

Tabela 4 - Coeficientes de correlação linear simples entre a caracterização inicial dos lotes e demais características avaliadas em sementes de milho, submetidas à germinação na temperatura de $31^{\circ} \mathrm{C}$. Londrina, 2012.

\begin{tabular}{|c|c|c|c|c|c|}
\hline \multirow{2}{*}{$\begin{array}{l}\text { Parâmetro } \\
\text { Observado }\end{array}$} & \multirow[b]{2}{*}{ P.C (\%) } & \multirow[b]{2}{*}{ G. $(\%)$} & \multirow[b]{2}{*}{ T.F (\%) } & \multirow[b]{2}{*}{ E.A (\%) } & \multirow[b]{2}{*}{ M.S.R (g) } \\
\hline & & & & & \\
\hline P.C &, $7521 * *$ &, $7514 * *$ &, $6956 * *$ &, $6891 * *$ &, $7114 * *$ \\
\hline $\mathrm{G}$ &, $7722 * *$ &, $8038 * *$ &, $7026 * *$ &, $6849 * *$ &, $7337 * *$ \\
\hline M.S.PA &, $8334 * *$ &, $6334 * *$ &, $5113 *$ &, $6751 * *$ &, $7441 * *$ \\
\hline M.S.R &, $7483 * *$ &, $6957 * *$ &, $6298 * *$ &, $6881 * *$ &, $8057 * *$ \\
\hline C.R &, $5252 * *$ &, $5676 * *$ &, $4745 *$ & ,3835 &, $5775 * *$ \\
\hline \multirow[t]{2}{*}{ C.PA } &, $4978 *$ &, $4822 *$ & ,3165 & ,3104 & ,396 \\
\hline & M.S.PA (g) & C.R (cm) & C.PA (cm) & E.C $(\%)$ & I.V.E \\
\hline P.C &, $7451 * *$ &, $6893 * *$ &, $6795 * *$ &, $6263 * *$ &, $7077 * *$ \\
\hline G &, $7713 * *$ &, $7083 * *$ & ,6929 ** &, $6216 * *$ &, $7112 * *$ \\
\hline M.S.PA &, $7212 * *$ &, $7415 * *$ &, $6761 * *$ &, $6251 * *$ &, $7473 * *$ \\
\hline M.S.R &, $7354 * *$ &, $7497 * *$ &, $6306 * *$ &, $6498 * *$ &, $7064 * *$ \\
\hline C.R &, $5673 * *$ &, $5849 * *$ &, 358 &, $4222 *$ &, $517 * *$ \\
\hline C.PA &, $4012 *$ &, $4528 *$ & ,3264 &, 307 &, $4423 *$ \\
\hline
\end{tabular}

***Significativo aos 5\% e 1\%. P.C: primeira contagem; G: germinação; T.F: teste de frio; E.A: envelhecimento acelerado; M.S.R: massa seca de raízes; M.S.PA: massa seca da parte aérea; C.R: comprimento de raízes; C.PA: comprimento da parte aérea; E.C: emergência a campo; I.V.E: índice de velocidade de emergência. 
Tabela 5 - Coeficientes de correlação linear simples entre a caracterização inicial dos lotes e demais características avaliadas em sementes de milho, submetidas à germinação na temperatura de $34^{\circ} \mathrm{C}$. Londrina, 2012.

\begin{tabular}{|c|c|c|c|c|c|}
\hline $\begin{array}{l}\text { Parâmetro } \\
\text { Observado }\end{array}$ & P.C (\%) & G. $(\%)$ & T.F (\%) & E.A $(\%)$ & M.S.R (g) \\
\hline P.C &, $7847 * *$ & ,8027** &, $7816 * *$ &, $8065 * *$ &, $7446 * *$ \\
\hline G &, $9259 * *$ &, $7917 * *$ &, $7237 * *$ &, $899 * *$ &, $8213 * *$ \\
\hline M.S.PA &, $8946 * *$ &, $649 * *$ &, $5177 * *$ &, $8156 * *$ &, $8593 * *$ \\
\hline M.S.R &, $8526 * *$ &, $7954 * *$ &, $7861 * *$ &, $8956 * *$ &, $8943 * *$ \\
\hline C.R &, $6306 * *$ &, $6222 * *$ &, $6183 * *$ &, $5672 * *$ &, $5637 * *$ \\
\hline \multirow[t]{2}{*}{ C.PA } &, $853 * *$ &, $5897 * *$ &, $4394 *$ &, $7248 * *$ &, $7557 * *$ \\
\hline & M.S.PA (g) & C.R (cm) & C.PA(cm) & E.C $(\%)$ & I.V.E \\
\hline P.C &, $6948 * *$ &, $699 * *$ &, $6264 * *$ &, $7755 * *$ &, $8162 * *$ \\
\hline G &, $771 * *$ &, $8131 * *$ &, $7887 * *$ &, $7971 * *$ &, $8615 * *$ \\
\hline M.S.PA &, $8377 * *$ &, $8898 * *$ &, $8148 * *$ &, $6885 * *$ &, $8205 * *$ \\
\hline M.S.R &, $8282 * *$ &, $7683 * *$ &, $728 * *$ &, $7896 * *$ &, $8334 * *$ \\
\hline C.R &, $4718 *$ &, $4361 *$ & ,3709 &, $5429 * *$ &, $5773 * *$ \\
\hline C.PA &, $7164 * *$ &, $7932 * *$ &, $7725 * *$ &, $5667 * *$ &, $7088 * *$ \\
\hline
\end{tabular}

*** Significativo aos 5\% e 1\%. P.C: primeira contagem; G: germinação; T.F: teste de frio; E.A: envelhecimento acelerado; M.S.R: massa seca de raízes; M.S.PA: massa seca da parte aérea; C.R: comprimento de raízes; C.PA: comprimento da parte aérea; E.C: emergência a campo; I.V.E: índice de velocidade de emergência.

quesitos de rapidez, objetividade, simplicidade, economia e reprodutibilidade, além de permitir a interseção dos dados obtidos em diferentes testes (CALIARI \& SILVA, 2001). Na temperatura de $34^{\circ} \mathrm{C}$, as variáveis porcentagem de germinação, primeira contagem, massa seca da parte aérea e de raízes, apresentaram correlação, ao $1 \%$ de significância, com todas as determinações realizadas na caracterização inicial dos lotes.

Além disso, espera-se que os resultados dos testes de vigor permitam distinguir com segurança os lotes de alto dos de baixo vigor e que as diferenças detectadas estejam relacionadas ao comportamento das sementes durante o armazenamento e após a semeadura (MARCOS FILHO, 2005), ou seja, os testes de vigor devem apresentar correlação com a emergência a campo (PESKE \& BARROS, 2003). Todos os parâmetros avaliados a $34^{\circ} \mathrm{C}$ também se correlacionaram, a $1 \%$ de significância, com a emergência e com o índice de velocidade de emergência a campo (Tabela 5).

As avaliações realizadas a $37^{\circ} \mathrm{C}$ foram as que menos apresentaram correlação com os testes da caracterização inicial dos lotes, sendo que a massa seca da parte aérea e raízes obtidas na temperatura de $37^{\circ} \mathrm{C}$ não se correlacionaram com nenhuma das determinações realizadas inicialmente (Tabela 6). Além da ausência de correlação entre algumas variáveis estudadas, os valores de correlações a $37^{\circ} \mathrm{C}$ foram menores, comparados às temperaturas de 31 e $34^{\circ} \mathrm{C}$.
A ausência e os menores valores de correlações significativas a $37^{\circ} \mathrm{C}$ podem ser explicados devido às baixas porcentagens de germinação e a inexistência de diferenças significativas da massa seca de raízes e parte aérea (Tabela 3). A temperatura de $37^{\circ} \mathrm{C}$ foi considerada drástica para a avaliação do vigor, visto que declínios acentuados na porcentagem de germinação do milho começam a ser observados a partir de $35^{\circ} \mathrm{C}$ (BORBA et al., 1995). Segundo SANS \& SANTANA (2005), temperaturas do solo próximas a $40^{\circ} \mathrm{C}$ podem prejudicar ou impedir a germinação das sementes.

A alta correlação das variáveis analisadas a $34^{\circ} \mathrm{C}$ com os diversos testes realizados na caracterização inicial dos lotes demonstram que a temperatura de $34^{\circ} \mathrm{C}$ foi a mais adequada para a avaliação do vigor das sementes de milho. Além disso, a porcentagem de germinação a $34^{\circ} \mathrm{C}$ apresentou os maiores valores de correlação com a primeira contagem, envelhecimento acelerado, emergência a campo e índice de velocidade de emergência.

\section{CONCLUSÃO}

A germinação sob temperatura de $34^{\circ} \mathrm{C}$ mostrou-se mais adequada para avaliação do potencial fisiológico de lotes de sementes de milho, com correlação alta e significativa com os testes laboratoriais e de emergência e índice de velocidade de emergência de plântulas no campo. 
Tabela 6 - Coeficientes de correlação linear simples entre a caracterização inicial dos lotes e demais características avaliadas em sementes de milho submetidas à germinação na temperatura de $37^{\circ} \mathrm{C}$. Londrina, 2012.

\begin{tabular}{|c|c|c|c|c|c|}
\hline $\begin{array}{l}\text { Parâmetro } \\
\text { Observado }\end{array}$ & P.C (\%) & G. $(\%)$ & T.F (\%) & E.A (\%) & M.S.R (g) \\
\hline P.C &, $5856 * *$ &, $6544 * *$ &, $7285 * *$ & ,6733** & ,745** \\
\hline G &, $6015 * *$ &, $6707 * *$ & $7415 * *$ & $6905 * *$ & $7588 * *$ \\
\hline M.S.PA &, 1212 & ,2022 & ,3046 &, 256 & ,2972 \\
\hline M.S.R &,- 1264 &,- 0296 &, 0968 & ,0886 &,- 0809 \\
\hline C.R &, $5462 * *$ &, $6058 * *$ &, $6669 * *$ &, $721 * *$ &, $6913 * *$ \\
\hline \multirow[t]{2}{*}{ C.PA } &, $6279 * *$ &, $6485 * *$ &, $6053 * *$ &, $5993 * *$ &, $7701 * *$ \\
\hline & M.S.PA (g) & C.R (cm) & C.PA(cm) & E.C (\%) & I.V.E \\
\hline P.C &, $6674 * *$ &, $555 * *$ &, $4777 *$ &, $65 * *$ &, $6203 * *$ \\
\hline G &, $685 * *$ &, $5818 * *$ &, $4984 *$ &, $6605 * *$ & $6289 * *$ \\
\hline M.S.PA & ,2992 & ,2802 & ,203 &, 2113 &, 227 \\
\hline M.S.R &,- 0302 &,- 0012 &, 1266 &, 1355 & ,0096 \\
\hline C.R &, $7194 * *$ &, $5848 * *$ &, $6412 * *$ &, $6883 * *$ &, $6563 * *$ \\
\hline C.PA &, $7298 * *$ &, $6765 * *$ &, $5597 * *$ &, $5919 * *$ &, $6663 * *$ \\
\hline
\end{tabular}

*** Significativo aos 5\% e 1\%. P.C: primeira contagem; G: germinação; T.F: teste de frio; E.A: envelhecimento acelerado; M.S.R: massa seca de raízes; M.S.PA: massa seca da parte aérea; C.R: comprimento de raízes; C.PA: comprimento da parte aérea; PE.C: emergência a campo; I.V.E: índice de velocidade de emergência.

\section{AGRADECIMENTOS}

À Coordenação de Aperfeiçoamento de Pessoal de Nível Superior (CAPES) pela concessão da bolsa.

\section{REFERÊNCIAS}

BRASIL, Ministério da Agricultura e Reforma Agrária. Regras para análise de sementes. Brasília: SNDA/ DNDV/ CLAV, 2009. 364p. Disponível em: <http://www.agricultura.gov.br/arq editor/ file/2946_regras_analise_sementes.pdf $>$. Acesso em: 30 abr. 2013.

BORBA, C.S. et al. Germinação de sementes de diversos genótipos de milho tropical (Zea mays L.) em diferentes temperaturas. Revista Brasileira de Sementes, Sete Lagoas, v.17, n.2, p.141144, 1995. Disponível em: <http://www.alice.cnptia.embrapa.br/ alice/bitstream/doc/488505/1/Germinacaosementes.pdf $>$. Acesso em: 30 abr. 2013.

CALIARI, M.F.; SILVA, W.R. Interpretação de dados de testes de vigor na avaliação da qualidade fisiológica de sementes de milho. Revista Brasileira de Sementes, Brasília, v.23, n.1, p.239251, 2001. Disponível em: <http://www.abrates.org.br/revista/ artigos/2001/v23n1/artigo34.pdf>. Acesso em: 04 mai. 2013.

CARVALHO, N.M.; NAKAGAWA, J. Sementes: ciência, tecnologia e produção. 5.ed. Jaboticabal: FUNEP. 2012. 590p.

CASEIRO, R.F.; MARCOS FILHO, J. Procedimentos para condução do teste de frio em sementes de milho: pré resfriamento e distribuição do substrato no interior da câmara fria. Revista Brasileira de Sementes, Londrina, v.24, n.2, p.6-11, 2002. Disponível em: <http://www.scielo.br/scielo.php?pid=s0101$31222002000200002 \&$ script $=$ sci arttext $>$. Acesso em: 02 mai. 2013. doi: 10.1590/S0101-31222002000100002.

DIAS, M.C.L.L.; BARROS, A.S.R. Avaliação da qualidade de sementes de milho. Londrina: IAPAR, 1995. 43p.

HALL, A.E. HeatStress and its Impact. 2001. Disponível em: $<$ http://www.plantstress.com/Articles/heat_i/heat_i.htm $>$. Online. Acesso em: 16 abr. 2012.
KRZYZANOWSKI, F.C. et al. Relato dos testes de vigor disponíveis para as grandes culturas. Informativo ABRATES, Londrina, v.1, n.2, p.15-50, 1991.

KRZYZANOWSKI, F.C. et al. Vigor de sementes: conceitos e testes. Londrina: ABRATES, 1999. 218p.

MARCOS FILHO, J. et al. Métodos para avaliação do vigor de sementes de soja, incluindo a análise computadorizada de imagens. Revista Brasileira de Sementes, Londrina, v.31, n.1, p.102-112, 2009. Disponível em: <http://www.scielo.br/scielo. php?pid=S0101-31222009000100012\&script $=$ sci_arttext $>$. Acesso em: 30 abr. 2013. doi: 10.1590/S0101-31222009000100012.

MARCOS FILHO, J. Fisiologia de sementes de plantas cultivadas. Piracicaba: FEALQ, 2005. 495p.

MENDONCA, E.A.F. et al. Testes de vigor em sementes de algodoeiro herbáceo. Revista Brasileira de Sementes, Londrina, v.30, n.3, p.001-009, 2008. Disponível em: < http://www.scielo.br/ scielo.php?script $=$ sci_arttext\&pid=S0101-31222008000300001>. Acessoem:04 mai.2013. doi: 10.1590/S0101-31222008000300001.

NAKAGAWA, J. Testes de vigor baseados na avaliação das plântulas. In: VIEIRA, R.D.; CARVALHO, N.M. (Ed). Testes de vigor de sementes. Jaboticabal: FUNEP, 1994. 164p.

NAKAGAWA, J. Testes de vigor baseados no desempenho de plântulas. In: KRZYZANOWSKI, F.C. et al. Vigor de sementes: conceitos e testes. Londrina: ABRATES, 1999. p.2.1-2.24.

PESKE, S.T.; BARROS, A.C.S.A. Produção de sementes. In: PESKE, S.T. et al. Sementes: fundamentos científicos e tecnológicos. Pelotas: UFPel, 2003. 418p.

SANS, L.M.A.; SANTANA, D.P. Cultivo do milho - clima e solo. Local: Embrapa Milho e Sorgo, 2005. Total de 4p. Disponível em: <http://ainfo.cnptia.embrapa.br/digital/bitstream/ CNPMS/15594/1/Com_38.pdf $>$. Acesso em: 04 mai. 2013.

SIMONI, F. et al. Sementes de Sorghum bicolor L. - Gramineae, submetidas ao estresse hídrico simulado com PEG (6000). Revista de Biologia e Ciências da Terra, Pernambuco, v.11, n.1, p.188-192, 2011. Disponível em: <http://www.redalyc.org/ pdf/500/50021097021.pdf $>$. Acesso em: 04 mai. 2013. 